\title{
Competitors in merger control: Shall they be merely heard or also listened to?
}

\author{
Thomas Giebe ${ }^{1} \cdot$ Miyu Lee ${ }^{2}$
}

Published online: 20 April 2020

(c) The Author(s) 2020

\begin{abstract}
There are legal grounds to hear competitors in merger control proceedings, and competitor involvement has gained significance. To what extent this is economically sensible is the focus of our game-theoretic analysis. The competition authority applies some welfare standard while the competitor cares about its own profit. In expectation, there is neither a pure conflict nor a complete alignment of interest. We distinguish hard and soft information and ask whether hearing the competitor might convey valuable but non-verifiable information to the authority. We identify a case where, based on the authority's verifiable information, the authority's decision is improved by following the competitor's selfish but non-verifiable communication. We argue that the practical relevance of this constellation is very limited, especially so under a consumer welfare standard. Thus, non-verifiable information should mostly be ignored. Complementary to our analysis, we provide empirical data of competitor involvement in EU merger cases and give an overview of the legal discussion in the EU and US.
\end{abstract}

Keywords Merger · Antitrust · European Commission · Signaling · Efficiency · Competitors $\cdot$ Game theory

JEL Classification $\mathrm{G} 34 \cdot \mathrm{K} 21 \cdot \mathrm{L} 4 \cdot \mathrm{C} 73 \cdot \mathrm{L} 2$

Electronic supplementary material The online version of this article (https://doi.org/10.1007/s1065 7-020-09649-3) contains supplementary material, which is available to authorized users.

Thomas Giebe

thomas.giebe@1nu.se

Miyu Lee

miyu.lee@post.harvard.edu

1 Department of Economics and Statistics, Linnaeus University, Växjö, Sweden

2 Klarna Bank AB, Stockholm, Sweden 


\section{Introduction}

Both in the European Union (EU) and the U.S., competitors have gained significance in merger control proceedings. EU merger law presently entitles competitors to submit their views on the notified merger in writing and in a formal hearing before the European Commission (Commission) makes a final decision. Additionally, competitors have been increasingly involved in the Commission's fact-finding and market investigation process. In the U.S., competitors' claims were traditionally treated restrictively but both the Department of Justice and the Federal Trade Commission have recently started to widen the extent of competitor participation in merger proceedings by conducting an 'open door' policy.

These recent procedural developments in merger control have motivated us to explore potential policy deficiencies which might arise out of a conflict between legal due process and economic efficiency aspects: while, on the one hand, we have regulatory, procedural and practical reasons to take into account the competitors' opinions such as their legal right to be heard or the authority's past heavy reliance on third-party input resulting from its information deficit due to limited resources; on the other hand, from an efficiency standpoint, there is reason to believe that a certain degree of temptation exists on the part of the competitors to manipulate the authority so as to achieve a decision maximizing their own profits rather than welfare.

Our goal in this paper is twofold. First, we document the growing significance and the legal discussion of competitor involvement in merger proceedings in the EU and the U.S. This is complemented by empirical data of EU merger cases. Second, we introduce and analyze a tractable game-theoretical model for the strategic interaction between competitors and the competition authority. From this analysis, we derive a policy recommendation.

We are particularly interested in the communication of subjective and non-verifiable information between the competitor and the authority. We employ cheap talk signaling games in which the competitor communicates with the authority. This communication is costless and non-binding and its content is not verifiable. It has no direct consequences but, depending on how it affects the authority's beliefs about the merger implications, it might reveal valuable information or it might be used to deceive the authority. The authority decides to either clear or block the merger based on its own, mostly verifiable, information and the competitor's message. This includes the option to ignore the competitor's communication.

We formally derive all perfect Bayesian pure- and mixed-strategy equilibria of the signalling game. They can be partitioned into equilibria where the authority ignores the competitor's message and takes a decision based on its own (verifiable) information only, and equilibria where it implements the competitor's preferred decision. In the latter case, the authority's decision is always superior, by the welfare standard applied, as compared to a decision under ignorance of the competitor's cheap talk. The situations in which the authority should 'listen' rather than 'hear' are characterized by a sufficient expected alignment of interest. They can easily be identified from the authority's own prior information. 
However, we argue that these situations are very unlikely to occur, especially so under a consumer welfare standard. This might provide a justification for the consumer welfare standard: under this standard, is seems clear that soft information should not be relied upon.

Relevant legal and economic literature is mentioned throughout the paper. Section 2 discusses the legal background and the procedural aspects of hearing competitors' views; Sect. 3 describes the model and motivates the use of signaling games; Sects. 4 and 5 present the most interesting pure- and mixed-strategy equilibria of the signaling game, respectively. Section 6 provides a discussion of the results as well as our policy recommendation. Section 7 concludes. The online supplementary material contains the detailed solution of the signaling games, as well as empirical data on EU merger cases.

\section{Competitor involvement in merger control}

\subsection{European Union}

Competitor involvement in EU merger control is explicitly set forth in the European merger law provisions: Within 7-10 days after receiving a merger notification the Commission sends out Article $11^{1}$ letters to the filing parties and interested third parties'. The law defines the latter usually as being competitors, suppliers and customers. ${ }^{2}$ The so-called Article 11 letters' main purpose is to gather information on the market in Phase 1. The Best Practice Guidelines further set forth that the Commission may consult third parties on methodological issues regarding data and information gathering in the relevant economic sector. ${ }^{3}$ Third parties showing sufficient interest may request in Phase 1 to be heard orally.

In Phase 2, the Commission sends to the involved third parties a non-confidential version of the Statement of Objections ${ }^{4}$ after which the third parties have the right to express their view in writing or orally in a formal hearing. ${ }^{5}$

Finally, the Commission states in its Best Practice Guidelines that it welcomes any individual submission apart from direct replies from questionnaires where third parties provide 'information and comments' considered relevant for the merger assessment. It may also invite those parties for meetings to discuss or clarify such issues further. ${ }^{6}$

The prevailing view among scholars and practitioners is that in most cases, the Commission will lack the internal market expertise upon receiving a notification,

\footnotetext{
1 Merger Regulation 139/2004.

2 Art. 11(c) of the Regulation 802/2004 (Implementing Regulation) implementing the Merger Regulation 139/2004, i.e., setting forth details on notifications, time limits, and hearings.

3 Best Practices on the conduct of EC merger control proceedings 2004, para 28.

4 Art. 16(1) Implementing Regulation.

5 Art. 16 and 18 Implementing Regulation.

6 para. 35.
} 
thereby granting a 'considerable scope' of comment to and relying heavily on the information provided by the third parties. ${ }^{7}$ Hearing Officers Durande and Williams of the Cabinet of the Commissioner agree that although the right for a formal hearing may in principle be denied by the Commission, the rights of the 'other involved third parties' which includes competitors must be considered as being much closer to those of a defendant in terms of procedural guarantees. ${ }^{8}$

\subsection{U.S.}

The U.S. have been traditionally more reserved in granting rights to competitors in merger proceedings. The responsible authorities, the U.S. Department of Justice (DoJ) and the Federal Trade Commission (FTC), took the view that competitors were more likely to complain about mergers which would render the market more competitive post merger. ${ }^{9}$ To competitors who tried to challenge a merger by way of an injunction ${ }^{10}$ or sue for damages, the Supreme Court usually denied standing to the competitors. ${ }^{11}$

However, while the DoJ and FTC were once resistant to hear competitors in pending merger proceedings, the practice has markedly changed in recent years. The most prominent case was AT\&T Inc.'s contemplated acquisition of T-Mobile USA, Inc. in 2011. ${ }^{12}$ Competitors Sprint Nextel and Cellular South opposed the merger and the agencies supported their efforts in gaining access to the documents relating to the merger. ${ }^{13}$ After their strong objections which were also supported by the U.S. and several states, AT\&T ultimately abandoned its efforts to acquire T-Mobile USA.

Given the recent shift in the agencies' stance towards competitors, practitioners in the U.S. have become conscious about the 'right strategy' competitors could take in merger proceedings, stating that the bigger role in merger review 'necessitates an additional layer of planning and strategy'. ${ }^{14}$

\subsection{Legal and strategic considerations in competitor involvement}

Apart from information-gathering purposes, the involvement of competitors as set forth by EU laws is partly motivated by the legal principle of granting anyone the right to be heard before an individual measure which would affect such person adversely is taken ${ }^{15}$ and partly by due process considerations. Legislators and legal

\footnotetext{
7 Van Bael and Bellis (2005, p. 861); Cleary Gottlieb Steen and Hamilton (2004, p. 4).

8 as compared to rights of a complainant in antitrust matters. See Durande and Williams (2005, p. 22).

9 Diesenhaus (1987, p. 2059), Van Arsdall and Piehl (2014).

10 Sec. 16 Clayton Act, 15 U.S.C. 26.

11 Cargill v. Monfort of Colorado, Inc., 107 S.Ct. 484 (1986).

12 AT\&T Inc., Description of Transaction, Public Interest Showing and Related Demonstrations, WT Docket No. 11-65 at 1, FCC filed April 21, 2011.

13 See detailed case discussion in Hundt (2011), Stucke and Grunes (2012, p. 196).

14 Van Arsdall and Piehl (2014, p. 2).

15 Art. 41 Charter of Fundamental Rights of the European Union.
} 
scholars might have taken the view upon drafting the rules that the competitors would always report truthfully to the deciding agency. A competitor raising serious doubts about a merger would thus be a reason to view the merger more critically.

While the competitors' right to be heard can be seen as a softer version of the usual rights of defense, ${ }^{16}$ practice shows that their participation is crucial if not essential in merger proceedings, as their involvement in Phase 2 proceedings shows:

We have looked into all Phase 2 proceedings between 1990 and 2013 and identified those cases where competitors were given the opportunity to voice their opinions. ${ }^{17}$ As can be seen in Fig. 1 which plots the ratio between competitor participation and Phase 2 cases, competitor involvement has radically increased since the reform and the ratio has stayed continuously at 1 . One can assume presently that all Phase 2 proceedings will entail the involvement of competitors, whereas in the past that was not necessarily the case.

We have further plotted the ratio of competitor objections to only those Phase 2 cases where competitors have been involved for the years from 1997 until 2013, see Fig. 2. In other words, only those instances were captured where competitors had a negative opinion on the merger proposed. As can be seen, competitors have been increasingly voicing concerns in the past years. Could it be because competitors have realized the strategic potential in merger proceedings or because more competition-enhancing mergers have been notified in the past years which did not find the competitors' approval?

In any case, scholars and practitioners now agree that competitors' opinions in merger proceedings shall be viewed with skepticism (see, e.g., Motta 2004, p. 240). The Commission has recently proceeded to add in its decisions a footnote saying that information furnished by third parties will not be taken at face value since 'the opinion provided might be biased to influence [its] decision-making process.' The footnote further states that the Commission will thus analyze competitors' opinions very carefully as they 'might have an interest in making the transaction of their competitors [...] more difficult[...]'. 18

The FTC stated already 25 years ago in an amicus brief that competitors 'stand to benefit from, and have no incentive to challenge, acquisitions that may lead to supracompetitive pricing. [They] have a substantial incentive to challenge acquisitions that will make their rivals more efficient, make their industry more competitive, and reduce the prices they can charge their customers. [...] [Competitors must be] prevented from using the antitrust laws for anticompetitive purposes.' 19

At the same time, the authorities are by definition market outsiders and must to some extent rely on the information provided by market insiders. They further face time and cost constraints which make it even more difficult to assess the state of a

\footnotetext{
16 Durande and Williams (2005, sp. 23).

17 The data has been collected by reviewing each Commission's decision in the relevant timespan which can be downloaded from the Commission's webpage: http://ec.europa.eu/competition/mergers/cases/. The data is contained in the online supplementary material.

18 See for example the decision in Ryanair/Aer Lingus III, M.6663, Feb. 27, 2013, para 28, footnote 18.

19 Brief for the United States and the Federal Trade Commission as Amici Curiae, Cargill v. Monfort.
} 
market or to anticipate the implication of a proposed merger on the market. Once competitors are playing a role in the market assessment, however, there is a potential risk for strategic abuse of the legal possibility to express their opinions by sending distorted signals to the authorities in order to promote their own interests (Motta 2004, p. 240). ${ }^{20}$

It has long been recognized that mergers generally exhibit a tradeoff between market power effects that tend to reduce welfare, and synergy effects that might increase welfare. For the competitors, the market power effect is supposed to be profit-increasing, as they can free-ride on the merging firms' output reduction, while synergy effects tend to reduce prices and therefore hurt the competitors' profits (see, e.g., Stigler 1950; Williamson 1968; Perry and Porter 1985).

For a given notified merger, it is difficult to say to what extent the competitors' and the authority's interests are aligned because both, the market power effect and some synergy effects, can be expected to be present in most mergers (Duso et al. 2011, p. 985).

Moreover, there is a large theoretical and empirical literature on mergers reporting very diverse effects with respect to welfare as well as insider and outsider profits depending on which aspects are relevant for a given merger. ${ }^{21}$ Neven and Röller (2002) recall that, based on standard oligopoly models, just by varying the degree of cost efficiencies we can get very diverse merger implications with respect to outsider profits, consumer surplus and total welfare. Banerjee and Eckard (1998), Clougherty and Duso (2009) present empirical evidence for both a post-merger increase as well as a decrease of outsider profits. Mergers might be unprofitable for both insiders and outsiders. This might happen in declining industries, when preemption is the motivation for mergers (Fridolfsson and Stennek 2005). Heubeck et al. (2006, p. 38) demonstrate how a merger can be desirable for both the competitor and the authority: Suppose the more efficient firm in a market is an outside firm and the merging firms do not realize any cost efficiencies. Then average marginal costs in the market might fall because the less efficient merged firm produces less than before, whereas the more efficient outsider will produce a larger share of the smaller total output. In spite of rising prices, total welfare might then rise.

\footnotetext{
${ }^{20}$ Harker et al. (2011) criticize competitors' preferential treatment under EU standing rules and argue that competitors' challenges often have strategic motives which are detrimental to consumer welfare.

21 Farrell (2012, p.22) stresses that "industries and their participants are endlessly idiosyncratic". Examples of such aspects are collusion (Miller and Weinberg 2014), quantity versus price competition (Salant et al. 1983; Deneckere and Davidson 1985), synergies (Banerjee and Eckard 1998; Farrell and Shapiro 2001), integration cost (Huck et al. 2004), internal capital-allocation (Mialon 2008), strategic market power (Huck et al. 2001), internal conflict (Banal-Estañol et al. 2008), managerial incentives (FaulíOller and Motta 1996; Kräkel and Müller 2015), managerial synergies (Matsusaka 1993), entry and exit (Davidson and Mukherjee 2007), managerial hubris (Roll 1986), technology (Lahiri and Ono 1988), firm-internal competition (Creane and Davidson 2004), multi-market presence (Werden et al. 1991), learning (Vermeulen and Barkema 2001), union organization (Lommerud et al. 2001) or uncertainty (Amir et al. 2009). See Datta et al. (1992) for a meta-analysis.
} 


\section{Competitor Participation/Phase 2 Cases}

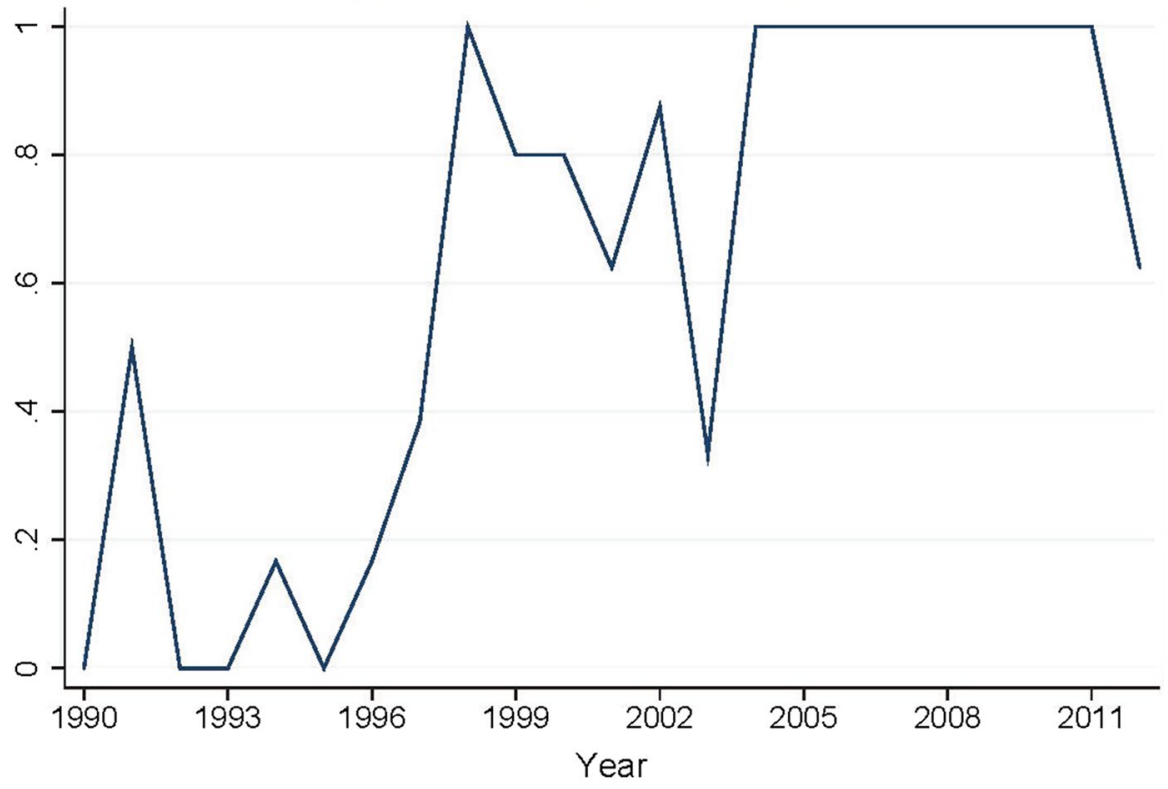

Fig. 1 Competitor participation as a share of Phase 2 cases, EU, 1990-2013

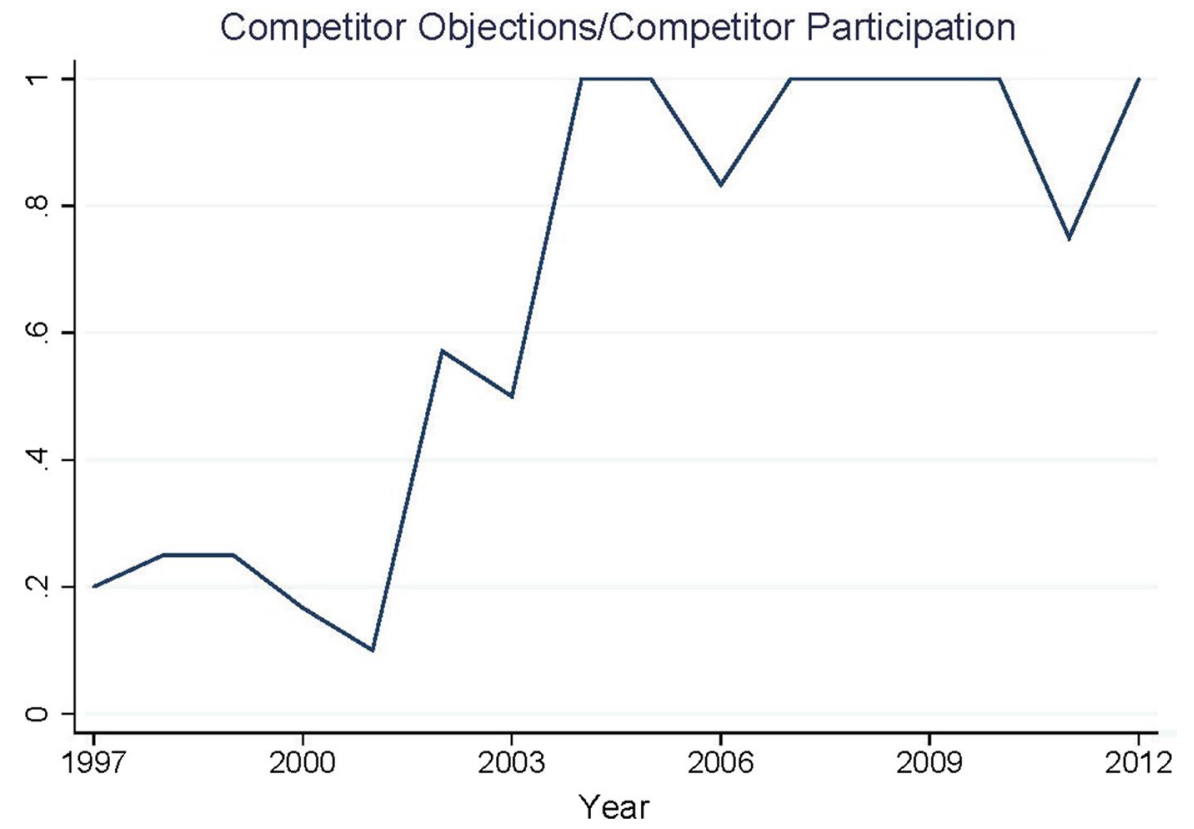

Fig. 2 Competitor objections as a share of Phase 2 cases with competitor involvement, EU, 1997-2013 


\section{Model}

In this section, we start with discussing the modeling of merger types. Then we motivate the use of signaling games before formally introducing them.

\subsection{Merger types}

Our analysis starts at a point in time when the authority has been notified of a planned merger. This implies that the merging firms are interested in a clearing decision, and we naturally assume that any communication between the merger insiders and the authority would be geared towards a clearing decision. Now, clearing the proposed merger has implications for the competitor's profits (П) and for welfare $(W)$, as measured by the welfare standard applied. We shall neglect the impact on the merging firms' profits because merging firms (apart from proposing the merger) will not strategically interact with competitors or the authority in our games. ${ }^{22}$

We assume that the authorities posit a welfare standard for their merger decisions and that competitor firms operate as profit-maximizers. For our analysis, it does not matter whether the authority, say, applies a total or a consumer welfare standard. This is because, as explained below, our analysis is based on a binary classification of mergers into 'desirable' and 'non-desirable' mergers from the point of view of the authority. This classification can be applied to any given welfare standard, implying that our results can be discussed for different welfare standards.

Denote by $\Pi$ and $W$ the change in the competitor's profit, resp. welfare, due to clearing a given merger, while blocking the merger preserves the status quo which is associated with 'no change'. Ignoring the possibility that a merger has no implications whatsoever, the authority's decision to clear a merger will either imply a welfare increase $(W>0)$ or decrease $(W<0)$, as compared to the status quo, while the competitor's profit will either increase $(\Pi>0)$ or decrease $(\Pi<0)$. Combining the above, we can assign each merger to one of four types. Obviously, this covers all conceivable merger types regardless of their practical relevance. Our classification implies that we are only interested in the sign of the change, rather than its magnitude. This binary classification corresponds to the binary nature of the authority's decision (either clear or block a merger), if we ignore remedies. Remedies will be discussed later on.

This case distinction allows us to separate the merger types where the authority's and the competitor's interests are aligned (both welfare and profit change in the same direction, up or down) from those that involve a conflict of interest, while observing the direction of the individual changes in each case. In our model, each of the four merger types has a prior probability $p_{i}$ derived from the authority's own collected

\footnotetext{
22 Most of the merger literature focusses on the merging firms' profits and neglects the competitor. An exception is González (2007) who explicitly deals with merger insiders and competitors as separate sources of information. Another exception is the taxonomy of mergers, proposed by Clougherty and Duso (2011, p.314). They distinguish between four merger types, depending on the merging firms' as well as the competitors' post merger profits.
} 
(verifiable) information on the given notified merger. This prior probability reflects the practical relevance of each merger type, and can be arbitrarily close to zero if a certain merger type is very unlikely to be relevant in a given situation. For our formal (game-theoretical) analysis, the practical relevance of a given merger type is immaterial, as we solve our games for all distributions of prior probabilities that the authority might attach to the merger at hand. Moreover, it is irrelevant what the reasons for the welfare and profit changes are (see the discussion in the Sect. 2.3).

For simplicity, we represent each merger type by a combination of $\Pi, W \in\{-1,1\}$, modeling the direction in which a clearance decision would alter welfare and the competitor's profit. This is, naturally, a very simplifying assumption. However, it allows us to keep the analysis straightforward and get clear results while still tackling the relevant strategic issues and preserving the basic interplay between conflict of interest and interest alignment. Apart from that, it might already be a challenging task in practice to place a given merger correctly within our four-type model. From a policy perspective, it might also not be practicable to analyze a more general model where $\Pi$ and $W$ are distributed on a finer grid, as this would require the authority to attach probabilities to each of the many types.

\subsection{Signaling game}

We set out to capture the characteristic interaction between the competitor(s) and the competition authority, taking into account the information available to each side and each party's interests. We want to study the economic implications of an existing (legal) institution, rather than design an (optimal) institution. ${ }^{23}$

Before formally defining the signalling game, we want to briefly discuss the role of the merging firms in our analysis. We assume that the merging firms and the outsiders have insider market knowledge that the authority is lacking. The role of the merging firms in our setup is twofold. First, they notify the authority of the planned merger. This step implies an expression of interest in a clearing decision. It is natural to assume that any soft communication from the merging firms would be geared towards a clearing decision. Second, the merging firms are part of the authority's fact-finding effort (gathering of verifiable information) which results in the prior probabilities $p_{i}$ used in our model.

Thus, our signaling game studies the communication between the competitor and the authority only. The game starts after a merger has been notified. ${ }^{24}$

\footnotetext{
${ }^{23}$ Lagerlöf and Heidhues (2005) study the interaction between the authority and merger insiders. They derive optimal merger control institutions in order to induce merger insiders to invest into the production of hard evidence about efficiency gains. Heller (2015) studies the effects of asymmetric information between the merging parties and the authority, taking into account the decision and cost of investigation of a merger proposal. Milgrom and Roberts (1986) discuss on a general level the problem of a decision maker who has to rely on the information of (and competition between) better-informed parties. Any information revealed is assumed to be verifiable.

24 This might be any type of merger. The set of notified mergers can be seen as endogenous to the merger policy, see, e.g., Sørgard (2009) or Nocke and Whinston (2010).
} 
Therefore, the profit and welfare implications of clearing this particular merger are given. The competitor, as a market insider, is assumed to know the merger type. The authority does not know the merger type, but it independently gathers information and tries to predict the consequences of the notified merger before making a decision. This prediction is summarized by the prior probabilities $p_{i}$ for every merger type. Assuming that the competitor is perfectly informed is of course a very simplifying assumption. We do this in order to provide the most favourable conditions for studying the theoretical limits of learning from soft information. ${ }^{25}$

We distinguish hard and soft information. Hard information is verifiable information that the authority gathers, potentially, from all involved parties, including the merging firms and the competitors. Hard information is provided upon the authority's request or voluntarily. In the model, hard information is represented by the distribution of prior probabilities $p_{i}$ of merger types. Soft information is non-verifiable information that arises from the communication between the authority and the competitor. In practical terms, soft information includes the always present spin of a statement, as well as the omission of specific pieces of information to support such spin, subtle biasing or overemphasizing (or de-emphasizing) pieces of information. In the model, soft information is represented by the competitor's messages and their interpretation in the equilibria of the signaling game.

The focus of our analysis is on communication of soft information. The question is whether there is a potential for the authority to gain valuable information that is not verifiable, or if, instead, it can only rely on hard information. In order to evaluate the theoretical scope of such competitor influence, we need to study information transmission under the most favourable conditions, i.e., we assume that the competitor has superior market knowledge that the authority is interested in. It is known from the signaling literature that, if there is no pure conflict of interest, we might expect transmission of valuable soft information. This information transmission then needs to be interpreted in the light of practical relevance. Of course, in reality, the competitor cannot sway the authority's opinion against available evidence, based on soft information only. Our contribution is to explore the theoretical limits of the authority's learning potential and to show that even under the most favourable conditions, the authority is unlikely to ever gain valuable insights from the competitor's soft communication.

We further assume that the competitor, before making its statement, has an idea of the authority's prior information, through press releases, communication with the authority and, especially in the EU, the Statement of Objections. Therefore, we treat the authority's prior information as common knowledge.

Combining its prior information with the soft information inferred from the competitor's statement, the authority either prohibits (blocks) or clears the notified merger. For simplicity, we leave out the option of a clearance decision with

\footnotetext{
25 In practice, also the competitor faces some uncertainty about merger implications. See, e.g., Cunha et al. (2014) for an explicit treatment of uncertain efficiency gains. See Farrell (2012) for an overview of the tools of analysis that are used to evaluate merger implications. See also Duso et al. (2010) for a discussion of the event study methodology, and the recent Miller (2014) on simulations of merger effects.
} 
remedies. ${ }^{26}$ Note that, due to the binary nature of our merger types, formally adding remedies to the model would not change the results at all, provided that the scope of the remedies is limited such that the merger type according to our classification does not change (e.g., from profit-increasing to profit-decreasing).

We have found cheap talk signaling games to be the most appealing approach to capture the procedural and informational features of merger review. ${ }^{27}$ These games capture the idea that the soft information submitted by the competitor is itself costless and has no direct consequences. It can only indirectly affect payoffs if it succeeds in altering the authority's perception (i.e., beliefs) of the situation sufficiently to affect the decision. In particular, the competitor can neither commit to tell the truth nor can lying be detected or has any cost. The difficulty for the authority in dealing with the competitor's communication therefore lies in the fact that it is not verifiable. Therefore, the authority must try to gauge the informational content of the competitor's statement, taking into account its own information and the fact that the competitor's interest need not, but can, coincide with the authority's.

We now formally set up a signaling game, i.e., a sequential game with players $S$ (also referred to as sender or competitor) and $R$ (also referred to as receiver or authority), and a non-strategic player nature. The timing, actions and information in this game are as follows:

1. Nature draws the merger type $t_{i} \in T=\left\{t_{1}, t_{2}, t_{3}, t_{4}\right\}$ with corresponding commonly known prior probabilities $p_{i}:=\operatorname{Pr}\left\{t_{i}\right\}>0$ where $\sum_{t_{i} \in T} p_{i}=1 .{ }^{28}$

2. $S$ observes $t_{i}$ and chooses a message $m_{j} \in M=\left\{m_{A}, m_{B}, m_{C}, m_{D}\right\}$. We refer to $S$ 's actions synonymously as reports or recommendations. The message set contains as many elements as there are merger types. Therefore, in principle (though not necessarily in equilibrium), the merger type can perfectly be communicated.

3. $R$ observes $m_{j}$ but does not observe $t_{i}$, and (knowing the probabilities $p_{i}$ ) chooses a decision $d_{k} \in D=\left\{d_{P}, d_{C}\right\}$, i.e. the decision either prohibits or clears the merger.

4. Payoffs $U^{R}\left(t_{i}, d_{k}\right)$ and $U^{S}\left(t_{i}, d_{k}\right)$ are realized, where

\footnotetext{
${ }^{26}$ Vasconcelos (2010) provides a theoretical treatment of remedies in an oligopoly model. We also leave out potential litigation following a decision. Gürtler and Kräkel (2009a) analyze litigation incentives depending on the type of takeover. Litigation cost are a separate source of inefficiencies which are typically neglected in the welfare analysis of takeovers, see Gürtler and Kräkel (2009b).

${ }^{27}$ The basic distinction in signaling games is between costly signals that directly affect payoffs (as, e.g., in the famous job market signaling of Spence (1973)) and signaling where the signal itself is 'cheap', i.e., costless, but might affect beliefs and, therefore, indirectly, payoffs (e.g., Farrell and Rabin 1996; Krishna and Morgan 2008). Signaling games have been successfully applied to many contexts, see, e.g., Riley (2001), Connelly et al. (2011). Crawford (1998) surveys experimental evidence on the working of cheap talk communication.

${ }^{28} \mathrm{We}$ assume strictly positive prior probabilities for each type in order to simplify the analysis. This is not a restrictive assumption as these probabilities can be arbitrarily small.
} 


$$
\begin{aligned}
& U^{R}\left(t_{i}, d_{k}\right)=\left\{\begin{array}{ll}
W_{i} & \text { if } d_{k}=d_{C} \\
0 & \text { if } d_{k}=d_{P}
\end{array}, \quad U^{S}\left(t_{i}, d_{k}\right)=\left\{\begin{array}{ll}
\Pi_{i} & \text { if } d_{k}=d_{C} \\
0 & \text { if } d_{k}=d_{P}
\end{array},\right.\right. \\
& t_{i} \in T,\left(W_{1}, W_{2}, W_{3}, W_{4}\right)=(-1,1,1,-1), \\
& \left(\Pi_{1}, \Pi_{2}, \Pi_{3}, \Pi_{4}\right)=(1,1,-1,-1) .
\end{aligned}
$$

Hence, there is a conflict of interest for types 1 and 3, whereas for types 2 and 4 both the competitor and the authority prefer the same decision (clearance for type 2 and blocking for type 4).

In order to simplify the presentation of mixed-strategy equilibria, we exclude certain non-generic constellations of the four prior probabilities of merger types. This rules out that indifference between actions is caused by the configuration of the priors rather than strategic decisions. Moreover, these assumptions imply a unique default decision (see next subsection).

In words, we assume that no two prior probabilities are equal, nor are there sums of two (resp. three) prior probabilities that are equal to the sum of the other two prior probabilities (resp. the remaining prior probability). These assumptions are not restrictive. Prior probabilities can be arbitrarily close to the excluded values. Formally,

Assumption 1 For any pair of merger types $t_{i}$ and $t_{j}$, we assume that $p_{i} \neq p_{j}$, $p_{i} \neq 1 / 2$ and $p_{i}+p_{j} \neq 1 / 2$.

\subsection{Default decision}

We define $d^{\text {default }}$ as the authority's optimal decision under complete ignorance of $S$ 's reports (soft information), for a given prior probability distribution of merger types. Thus, the default decision is the decision that relies on verifiable evidence only. Absent any signals by $S$, it is optimal for $R$ to implement the decision that implies a higher expected welfare, based on $R$ 's priors. In particular, the notified merger should be cleared $\left(d_{C}\right)$ if the merger is more likely to be welfare-improving rather than welfaredecreasing, i.e., $p_{2}+p_{3}>p_{1}+p_{4}$, and prohibited $\left(d_{P}\right)$ otherwise.

Therefore, the default decision is

$$
d^{\text {default }}= \begin{cases}d_{C} & \text { if } p_{2}+p_{3}>p_{1}+p_{4} \\ d_{P} & \text { otherwise }\end{cases}
$$

The corresponding expected welfare (change) is

$$
\begin{aligned}
E\left[W \mid d^{\text {default }}\right] & = \begin{cases}\sum_{t_{i} \in T} p_{i} W_{i} & \text { if } d^{\text {default }}=d_{C}, \\
0 & \text { otherwise, }\end{cases} \\
& = \begin{cases}-p_{1}+p_{2}+p_{3}-p_{4}>0 & \text { if } p_{2}+p_{3}>p_{1}+p_{4}, \\
0 & \text { otherwise }\end{cases}
\end{aligned}
$$




\section{Pure-Strategy equilibria}

A pure strategy of $S$ is a function $m\left(t_{i}\right), t_{i} \in T$, a pure strategy of $R$ is a function $d\left(m_{j}\right), m_{j} \in M$. Conditional on observing message $m_{j} \in M, R$ 's belief about the merger type is denoted by the probability distribution $\mu_{i}^{j}:=\operatorname{Pr}\left\{t_{i} \mid m_{j}\right\} \geq 0, t_{i} \in T$. Denote by $T_{x} \subset T$ the set of merger types for which $S$ sends the message $m_{x} \in M$ in any given equilibrium (candidate). Thus, $T_{A}, T_{B}, T_{C}$ and $T_{D}$ together are a partitioning of the type set.

Our equilibrium concept is pure-strategy perfect Bayesian equilibrium. Therefore, in addition to the above belief system, we require that $R$ 's decision $d_{k} \in D$ is payoff-maximizing, i.e, the optimal decision $d^{*}\left(m_{j}\right)$ conditional on observing message $m_{j}$ satisfies

$$
d^{*}\left(m_{j}\right) \in \arg \max _{d_{k} \in D} \sum_{t_{i} \in T} \mu_{i}^{j} U^{R}\left(t_{i}, d_{k}\right)
$$

Similarly, $S$ 's message $m_{j} \in M$ must be optimal, given the observed type $t_{i}$ and $R^{\prime} s$ optimal choice $d^{*}\left(m_{j}\right)$, i.e., the optimal message $m^{*}\left(t_{i}\right)$ satisfies

$$
m^{*}\left(t_{i}\right) \in \arg \max _{m_{j} \in M} U^{S}\left(t_{i}, d^{*}\left(m_{j}\right)\right)
$$

Finally, for each message $m_{j} \in M$ that is played by $S$ on the equilibrium path, $R$ 's beliefs on the information set corresponding to $m_{j}$ must follow from Bayes' rule and $S$ 's strategy. Formally, for each message $m_{j} \in M$ for which there is a type $t_{i} \in T$ with $m^{*}\left(t_{i}\right)=m_{j}$ (or, equivalently, $T_{j} \neq \emptyset$ ),

$$
\mu_{i}^{j}=\frac{p_{i}}{\sum_{t_{s} \in T_{j}} p_{s}} .
$$

An equilibrium is denoted by the players' complete strategies and $R$ 's consistent belief system.

$$
\left\{\left\{m^{*}\left(t_{i}\right) \forall t_{i} \in T\right\},\left\{d^{*}\left(m_{j}\right) \forall m_{j} \in M\right\},\left\{\mu_{i}^{j} \forall t_{i} \in T, m_{j} \in M\right\}\right\}
$$

We constructively derive all pure-strategy equilibria. Equilibrium candidates can be distinguished by $S$ 's strategy $\left(m_{i}, m_{j}, m_{k}, m_{l}\right)$, where the first entry is the message sent if the merger type is $t_{1}$, the second for merger type $t_{2}$ etc. and $m_{i}, m_{j}, m_{k}, m_{l} \in M$.

The analysis of equilibria can be simplified substantially as follows. ${ }^{29}$ The informational content of each pure strategy of $S$ corresponds to a partitioning of the type set. For instance, the pure strategy $\left(m_{A}, m_{B}, m_{A}, m_{A}\right)$ partitions the type set into $T_{A} \in\left\{t_{1}, t_{3}, t_{4}\right\}$ and $T_{B}=\left\{t_{2}\right\}$. In words, the merger type 2 is fully revealed in this candidate whereas the other three types are bunched together by sending the same message for all of them. As a consequence, the pure strategy $\left(m_{A}, m_{B}, m_{A}, m_{A}\right)$ has

\footnotetext{
${ }^{29}$ As there are four messages available for each merger type, we have $4^{4}=256$ pure-strategy equilibrium candidates.
} 
the same informational content as $\left(m_{D}, m_{B}, m_{D}, m_{D}\right)$ and will implement the same equilibrium decision. ${ }^{30}$

By the above, the pure-strategy equilibrium candidates can conveniently be distinguished by their informational content, i.e., the form of the partitioning of the type set $T$ they induce. This results in five classes of equilibrium candidates which we formally analyze in the onliny supplementary material.

We denote the set of equilibrium messages by $\tilde{M}$. Thus, an off-equilibrium message $m_{y}$ is denoted by $m_{y} \notin \tilde{M}$. Arbitrary (and different) types are denoted by $t_{i}, t_{j}, t_{k}$, $t_{l} \in T$, and arbitrary (and different) messages by $m_{w}, m_{x}, m_{y}, m_{z} \in M$.

In summary, we identify two classes of pure-strategy equilibria: Those in which the authority implements the default decision, ignoring the competitor's (soft) communication, and those equilibria in which the authority follows the competitor's recommendation.

The latter class of equilibrium is the only 'interesting' result from the perspective of our research question. We look at this result in more detail now.

In these equilibria, $R$ 's optimal decision after each message is different. But this implies that $S$ can 'control' $R$ 's decision by sending the appropriate message. This can only be an equilibrium if the interests of $R$ and $S$ are sufficiently aligned, such that $S$ does not have an incentive do 'mislead' $R$.

Intuitively, this alignment of interest implies that the authority already expects (based on verifiable information), that it does not have a conflict of interest with the competitor. More precisely, the authority expects that if the merger is profit-increasing for the competitor, then it is more likely to be welfare-increasing rather than welfare-decreasing $\left(p_{2}>p_{1}\right)$. At the same time, the authority expects that a profitdecreasing merger is more likely welfare-decreasing rather than welfare-increasing $\left(p_{4}>p_{3}\right)$.

Therefore, if there is no conflict of interest, the authority can rely on the competitor to truthfully reveal the profit implications of clearing the merger. This implies that the authority learns truthful information which improves the authority's knowlege about the merger type and thus, in expectation, improves its decision.

Formally (see Lemma 3, part 3, and its proof in the online supplementary material), the game has pure-strategy equilibria in which one message, respectively, is associated with pairs of merger types that have the same implication for the competitor's profit, i.e., there is one message for profit-increasing mergers, and one for profit-decreasing mergers. Formally, the two messages partition the type space into $T_{x}=\left\{t_{1}, t_{2}\right\}$ and $T_{y}=\left\{t_{3}, t_{4}\right\}$, while $R$ implements $S$ 's preferred decision. Denoting $t_{s} \in T_{x}, t_{u} \in T_{y}$ and off-equilibrium-path messages $m_{z} \notin \tilde{M}$, the 'selfish' equilibrium has the existence condition $p_{3}<p_{4}, p_{1}<p_{2}$, i.e. the required alignment of interest between $S$ and $R$ that supports the equilibrium. ${ }^{31}$ The equilibrium is formally described by

\footnotetext{
${ }^{30}$ In the signaling literature, this is referred to as inessential multiplicity of signaling languages, see, e.g., Crawford (1998). We distinguish only the essentially different equilibrium candidates.

31 Given that this equilibrium exists $\left(p_{3}<p_{4}, p_{1}<p_{2}\right)$, beliefs off the equilibrium path are unrestricted, as $S$ never has an incentive to deviate, because $S$ 's preferred decision is implemented in equilibrium.
} 


$$
\begin{aligned}
& T_{x}=\left\{t_{1}, t_{2}\right\}, T_{y}=\left\{t_{3}, t_{4}\right\}, \\
& m^{*}\left(t_{s}\right)=m_{x}, m^{*}\left(t_{u}\right)=m_{y}, \\
& d^{*}\left(m_{x}\right)=d_{C}, d^{*}\left(m_{y}\right)=d_{P}, d^{*}\left(m_{z}\right) \in\left\{d_{P}, d_{C}\right\}, \\
& \mu_{s}^{x}=\frac{p_{s}}{p_{1}+p_{2}}, \mu_{s}^{y}=0, \mu_{u}^{y}=\frac{p_{u}}{p_{3}+p_{4}}, \mu_{u}^{x}=0, \mu_{i}^{z} \geq 0 .
\end{aligned}
$$

We discuss these results in Sect. 6.

\section{Mixed-strategy equilibria}

In this section, we discuss the game's perfect Bayesian equilibria in mixed strategies. A mixed strategy means any strategy where $S$ randomizes (i.e. mixes) between at least two messages for at least one type, or a strategy where $R$ mixes between decisions after at least one message on the equilibrium path.

We constructively derive all mixed-strategy equilibria in a series of lemmas in the online supplementary material. While the model and game remain the same as before, we introduce new notation for mixed strategies. Denote the probability that $S$ sends message $m_{x}$ for type $t_{i}$ by ${ }^{32}$

$$
\tilde{p}_{i}^{x}=\operatorname{Pr}\left\{m_{x} \mid t_{i}\right\} \in[0,1], t_{i} \in T, m_{x} \in M, \sum_{m_{x} \in M} \tilde{p}_{i}^{x}=1 .
$$

A complete strategy of $S$ is therefore given by 16 probabilities $\tilde{p}_{i}^{x}$ for all type-message combinations. Similarly, denote the probability that $R$ clears the merger $\left(d_{C}\right)$ after observing message $m_{x}$ by $\tilde{p}_{x}^{C 33}$ :

$$
\tilde{p}_{x}^{C}=\operatorname{Pr}\left\{d_{C} \mid m_{x}\right\} \in[0,1], \forall m_{x} \in M .
$$

As there are only two decisions, a complete strategy of $R$ can be represented by four clearance probabilities $\tilde{p}_{x}^{C}$, corresponding to the four messages $m_{x} \in M$. Therefore, a mixed-strategy equilibrium is formally characterized by

$$
\left\{\left\{\tilde{p}_{i}^{x}, \forall m_{x} \in M, t_{i} \in T\right\},\left\{\tilde{p}_{x}^{C}, \forall m_{x} \in M\right\},\left\{\mu_{i}^{x}, \forall t_{i} \in T, m_{x} \in M\right\}\right\} .
$$

Again, equilibria either implement the default decision or $S$ 's preferred decision. In the latter, 'selfish' equilibrium, decisions are again always $S$ 's preferred decisions because otherwise $S$ would deviate to a message that implements the preferred decision. As several messages implement the same decision, $S$ is indifferent between these messages, respectively, and is therefore willing to mix. In equilibrium, we only require that $R$ 's best response remains to implement $S$ 's selfish decisions. These 'selfish' mixed-strategy equilibria do not deliver any new insights in addition to

\footnotetext{
$\overline{32}$ In this notation, the pure strategy $m\left(t_{i}\right)=m_{A}$ is now denoted as $\tilde{p}_{i}^{A}=1$.

33 In this notation, the pure strategy $d\left(m_{A}\right)=d_{P}$ is now denoted as $\tilde{p}_{A}^{C}=0$.
} 
what we learned from the pure-strategy 'selfish' equilibria. They also have the same existence condition $\left(p_{2}>p_{1}\right.$ and $\left.p_{3}<p_{4}\right)$ and interpretation as before. The formal statement is found in Lemma 8 in the online supplementary material.

We discuss these results in Sect. 6.

We mention that, based on our analysis, it is easy to also analyze a 'two-message institution', in which the authority restricts the message space to two messages only, $M=\left\{m_{A}, m_{B}\right\}$. Intuitively, this can be understood as simply asking for the competitor's recommendation to either clear or block the merger. This adresses the question of whether the authority can gain anything by strategically restricting the message space, thus potentially limiting the competitor's ability to mislead. As it turns out, however, the results do not lead to qualitatively different conclusions compared to the main analysis. This two-message game is formally defined and solved in the online supplementary material.

\section{Discussion and policy recommendation}

Combining our results, we distinguish two classes of equilibria (including pure- and mixed-strategy equilibria): All equilibria implement either the default decision or the competitor's preferred decision, with certainty, respectively. There is no equilibrium in which the authority plays a mixed strategy. Only the competitor ever mixes between messages. In any mixed equilibrium, $S$ 's strategies are 'close to' the pure strategies of a corresponding pure-strategy equilibrium, such that $R$ 's pure best response is the same as in the corresponding pure-strategy equilibrium.

The basic intuition for pure-strategy equilibria is as follows. The authority has two options. First, it might just ignore the competitor's message. Then the default decision is taken, and any message by $S$ is a best response. Second, it might act on the message. This is equivalent to saying that the authority makes its decision conditional on the message observed. Thus, it takes a specific decision after observing a certain (subset of the) feasible message(s), while taking the opposite decision conditional on observing the remaining message(s). But given this reaction of the authority, the competitor can basically control the authority's decision by sending (one of) the message(s) after which the authority implements $S$ 's preferred decision. Therefore, a message-contingent decision can only occur in equilibrium if the authority intends to directly implement the competitor's preferred decision. We conclude that either the authority must ignore the message, or it must implement the competitor's preferred decision in equilibrium.

The intuition for the selfish mixed-strategy equilibria is similar to that for the selfish pure-strategy equilibria. The (insubstantial) difference is that the competitor mixes between pairs of messages, but the messages within a pair have the same meaning in equilibrium, i.e., two messages recommend to block the merger, while 
the other two recommend a clearance decision. In this sense, two of the messages are redundant. ${ }^{34}$

All other mixed-strategy equilibria implement the default decision. The intuition here is that, given that $R$ implements the default, $S$ is indifferent between messages and there is a range of (pure and mixed) strategies that leave $R$ 's best response unchanged. The range of mixed strategies is larger the more certain $R$ 's default decision goes in one or the other direction.

We have shown that the game does not have pure-strategy equilibria in which more than two messages are played. Moreover, whenever more than two messages are used in mixed-strategy equilibria, then several messages have the same meaning, making the additional messages inconsequential and redundant. Thus, the competitor strategically conceals information by choosing a 'crude' language. ${ }^{35}$

Intuitively, using more than two (essentially different) messages reveals too much information to the authority, from the point of view of the competitor. Then the conflict of interest becomes payoff-relevant too often. In order to prevent this, $S$ either does not reveal any information (or only so much that the default decision remains $R$ 's best response), or if interests are sufficiently aligned, $S$ reveals carefully tailored information to $R$. In the selfish equilibrium, $S$ truthfully reveals the profit implications of the merger only, and the information revealed ensures that $S$ 's preferred decision is taken, while preventing $R$ from finding out the actual merger type and its welfare implications.

In general terms, our results are in line with the theoretical literature on cheap talk signaling (e.g., Crawford and Sobel 1982) as follows. Although we assume that the competitor knows the merger type, there is, given the authority's uncertainty, neither a pure conflict of interest, nor are interests completely opposed. Because of this, we can expect to find equilibria in which the competitor's information is partially revealed. However, this only happens if interests are sufficiently aligned, which is the case whenever the selfish equilibrium exists. Due to the potential conflict of interest, there cannot be full information revelation. Similarly, alignment of interest is insufficient for many prior distributions (i.e., merger situations), which results in the default decision in equilibrium. In some of these equilibria that implement the default, there is some information transmission. However, the competitor carefully reveals only so much information that the default decision remains a best response. In this sense, the information revealed is inconsequential and its revelation does not hurt the competitor.

In order to prepare a policy recommendation, we establish the payoff superiority of the selfish equilibria.

Proposition 1 Suppose the selfish equilibria exist, i.e., $p_{1}<p_{2}$ and $p_{3}<p_{4}$. In these equilibria, the authority's expected welfare and the competitor's expected profit are larger than in any other equilibrium. This applies to the selfish equilibria in pure

\footnotetext{
34 This explains why there is no selfish mixed-strategy equilibrium in the two-message game: This equilibrium requires four messages.

35 The nature of this result is well-known in the cheap talk literature, see Crawford and Sobel (1982).
} 
strategies of the four-and two-message games as well as the selfish equilibria in mixed strategies of the four-message game.

By Proposition 1, whenever they exist, the selfish equilibria can be considered to be the natural solution of the signaling games, as they are strictly 'preferred' by both the competitor and the authority.

Whenever a selfish equilibrium does not exist, we have shown that any equilibrium implements the default decision. Therefore, in these cases, the authority need not listen to the content of the competitor's communication and optimally and straightforwardly implements the default decision, based on its own prior and verifiable information.

Let us now look in detail at the implications of the selfish equilibria where $S$ communicates its preferred decision and $R$ implements it. The formal condition for this equilibrium is

$$
p_{1}<p_{2}, \quad p_{3}<p_{4} .
$$

This constellation of prior information is compatible with $d_{P}$ or $d_{C}$ being the default decision. It means that if the competitor, through its communication, reveals that the merger type is profit-increasing (type 1 or 2), then the authority, based on its own information, must expect that the competitor's preferred (clearing) decision is more likely to be welfare-increasing than decreasing. Simultaneously, it must hold that blocking the merger is optimal by the authority's prior information should the competitor reveal that the merger type is profit-decreasing (3 or 4).

Why is the selfish equilibrium welfare-superior to the default decision (Proposition 1)? Clearly, it reveals valuable information to the authority: The competitor, through the selfish recommendation, truthfully reveals whether the actual merger type is profit-increasing ( 1 or 2 ) or profit-decreasing ( 3 or 4 ), thereby truthfully excluding the two remaining types. Combining this truthful information with the authority's own prior information should intuitively improve the quality of the authority's decision. The price the authority pays for this information is to implement the competitor's preferred decision. Nevertheless, the existence condition of the selfish equilibrium, (12), ensures that the authority follows the competitor's recommendation only if that increases expected welfare as compared to ignoring the competitor. Intuitively, in any equilibrium, the authority plays a best response based on all available information, and it always has the option to implement the default. Therefore, a decision different from the default will only be taken if it is superior.

As mentioned above, the competitor intentionally sends a crude signal by only revealing a pair of merger types rather than the actual merger type. For instance, if the competitor reveals that the merger type is profit-increasing (types 1 or 2), the authority will clear the merger if it thinks, by (12), that welfare is more likely to increase than decrease given this information. If the actual merger type is 2 , then the authority's decision will be ex post welfare-maximizing, whereas, if it is type 1 , the decision will be wrong. In expectation, however, clearance is the right decision. If, instead, the competitor revealed the actual type, then nothing would 
change if the merger were 2 , but in case of type 1 , the authority would block the merger, hurting the competitor. Given this, it is better for the competitor to conceal the actual type.

Policy Recommendation Based on its own (prior and hard) information about the likely merger implications, the authority should check if condition (12) holds or not. In plain words, this condition is: Conditional on the merger being profit-increasing for the competitor, welfare must be expected to increase after clearance, and, conditional on the merger being profit-decreasing, welfare must be expected to decrease after clearance. If this condition holds, the authority can ask the competitor directly whether the merger will increase or decrease the competitor's profit, while asking for welfare implications is not sensible by our analysis. Then the authority should implement the competitor's preferred decision. It can take for granted that the information is truthful as lying is not in the competitor's interest. Equivalently, one might ask for a recommendation to either clear or block the merger, but should understand that the response will follow the competitor's selfish interest. If (12) does not hold, implement the default decision, i.e., the optimal decision under ignorance of the competitor's communication.

Derived from this recommendation, we emphasize that the quality of the authority's own prior gathering of hard information is crucial. This prior information a) decides whether listening to the competitor's nonverifiable communication is the optimal policy, and, b), it is the basis for the default decision.

Relevance What is the practical relevance of the alignment of interest between the authority and the competior, summarized in condition (12) as a requirement for the selfish equilibrium? Consider the condition $p_{1}<p_{2}$, i.e., conditional on being profit-increasing, the merger is more likely to increase rather than decrease welfare. This constellation seems very unrealistic if a consumer welfare standard is applied. Therefore, our results might give a justification for the consumer welfare standard: under a consumer welfare standard, competitors' soft information is not worth listening to. ${ }^{36}$ Note, however, that this condition is easier to satisfy under a total welfare standard. As an example for horizontal mergers, see, e.g., Heubeck et al. (2006, p. 38). Intuitively, this aligned interest can occur if the outsider is more efficient than the merging firms, such that after the merger, the outsider contributes relatively more production at low cost than the merged firms. Then total welfare as well as the competitor's profit can increase. As an example for vertical mergers, consider Salinger (1988, p.355) who shows that when foreclosure of outsiders in input markets is concerned, the interests of outsiders and the authority can be aligned both when welfare goes down (case of foreclosure) as well as when welfare goes up (absence of foreclosure).

Summarizing, we think that under a consumer welfare standard, the authority should rely on verifiable information only. Under a total welfare standard, however, it is a bit more open to argument whether soft information should be taken into account.

\footnotetext{
${ }^{36}$ See, e.g., Lyons (2003), Neven and Röller (2005), Pittman (2007) for other arguments in favor of a consumer welfare standard.
} 


\section{Conclusion}

Our paper sets up a formal game-theoretical model for the strategic interactions between competitor and authority in merger proceedings. This effort follows the spirit of information economics, which understands information asymmetries as a major driving force of economic decision making and should therefore be in the focus of policy making. ${ }^{37}$

The goal of this paper was to outline the extent of usefulness and abuse of hearing competitors' nonverifiable communication in order to derive a recommendation as to how to distinguish between cases where the authority can only rely on hard information of competitors, and those where additional soft information can improve the authority's decision.

In order to address our research question, we have employed a two-step procedure. First, we have studied information transmission using signaling games, analyzing all conceivable merger scenarios, including realistic and unrealistic merger implications. Second, we have interpreted the practical relevance of the cases in which, theoretically, there is learning potential for the authority.

Our main theoretical result is that the authority should generally ignore the competitor's recommendation, with one exception: If the interests of both parties are statistically aligned in a certain way, the authority should straightforwardly implement the competitor's recommendation. We have argued that the latter situation is unlikely to occur in reality, especially so under a consumer welfare standard.

The decision of whether to hear or to listen is based entirely on the authority's own and mostly verifiable information. Moreover, if it is optimal to ignore the competitor's subjective communication, the authority's decision is, again, based on verifiable information. Because of this, the competition authorities should focus on the quality of their own information gathering effort. This includes hard information obtained from the competitors as well as the merging firms.

In our analysis we made simplifying assumptions regarding merger types and the information structure in order to obtain a tractable model. In particular, competitors in practice are likely to be uncertain about the merger implications. Apart from that, we think that as long as there is relevant information on the side of the competitor that is not available to the authorities, and is not verifiable, the basic logic of our results applies: In theory, there are situations in which it is in both sides' interest to communicate some of that information and act on it, understanding that this information will not be complete and it will necessarily have to be profitable for both sides. These theoretical situations have to be interpreted in the light of practical relevance.

While our initial discussion documents a growing significance of competitor involvement in both the US and the EU, our supporting data only covers EU merger cases. Moreover, our analysis mainly addresses the EU merger control proceedings and the theory that the inquisitorial system might result into the authority potentially being more prone to outsider's influence than in the US and its adversarial system.

There is a lot of room for future research. Our analysis does not apply if remedies have such magnitude as to change the merger type in our classification, and we have

${ }^{37}$ See, e.g., Stiglitz (2002). 
neglected litigation. Moreover, it would be interesting and relevant to simultaneously look at the strategic production of soft and hard evidence, and to include both insiders and outsiders in a simultaneous analysis.

Acknowledgements Open access funding provided by Linnaeus University. We thank Özlem BedreDefolie, Helmut Bester, Benno Bühler, Gianmarco Calanchi, Joseph Clougherty, Tomaso Duso, Hans W. Friederiszick, Radosveta Ivanova-Stenzel, Ulrich Kamecke, Matthias Lang, Patrick Rey, Claudia Salim, Jan-Peter Siedlarek, Roland Strausz, three anonymous referees, participants of EARIE 2015 and the Mikroökonomisches Kolloquium of Humboldt University and Free University Berlin for helpful comments and discussion, Regine Hallmann for technical support, Matthias Menzel, Felix Bönisch and Tilman Fries for library and data assistance. This research was supported by the Deutsche Forschungsgemeinschaft (DFG) through CRC 649 Economic Risk.

Open Access This article is licensed under a Creative Commons Attribution 4.0 International License, which permits use, sharing, adaptation, distribution and reproduction in any medium or format, as long as you give appropriate credit to the original author(s) and the source, provide a link to the Creative Commons licence, and indicate if changes were made. The images or other third party material in this article are included in the article's Creative Commons licence, unless indicated otherwise in a credit line to the material. If material is not included in the article's Creative Commons licence and your intended use is not permitted by statutory regulation or exceeds the permitted use, you will need to obtain permission directly from the copyright holder. To view a copy of this licence, visit http://creativecommons.org/licen ses/by/4.0/.

\section{References}

Amir, R., Diamantoudi, E., \& Xue, L. (2009). Merger performance under uncertain efficiency gains. International Journal of Industrial Organization, 27, 264-273. https://doi.org/10.1016/j.ijind org.2008.08.006.

Banal-Estañol, A., Macho-Stadler, I., \& Seldeslachts, J. (2008). Endogenous mergers and endogenous efficiency gains: The efficiency defence revisited. International Journal of Industrial Organization, 26, 69-91. https://doi.org/10.1016/j.ijindorg.2006.10.007.

Banerjee, A., \& Eckard, E. W. (1998). Are mega-mergers anticompetitive? Evidence from the first great merger wave. The Rand Journal of Economics, 29, 803-827. https://doi.org/10.2307/2556095.

Cleary Gottlieb Steen \& Hamilton (2004). EU merger control: A brief history.

Clougherty, J. A., \& Duso, T. (2009). The impact of horizontal mergers on rivals: Gains to being left outside a merger. Journal of Management Studies, 46, 1365-1395. https://doi.org/10.111 1/j.1467-6486.2009.00852.x.

Clougherty, J. A., \& Duso, T. (2011). Using rival effects to identify synergies and improve merger typologies. Strategic Organization, 9, 310-335. https://doi.org/10.1177/1476127011421536.

Connelly, B. L., Certo, S. T., Ireland, R. D., \& Reutzel, C. R. (2011). Signaling theory: A review and assessment. Journal of Management, 37, 39-67. https://doi.org/10.1177/0149206310388419.

Crawford, V. (1998). A survey of experiments on communication via cheap talk. Journal of Economic theory, 78, 286-298. https://doi.org/10.1006/jeth.1997.2359.

Crawford, V. P., \& Sobel, J. (1982). Strategic information transmission. Econometrica, 50, 1431-1451. https://doi.org/10.2307/1913390.

Creane, A., \& Davidson, C. (2004). Multidivisional firms, internal competition, and the merger paradox. Canadian Journal of Economics/Revue canadienne d'économique, 37, 951-977. https://doi.org/10.1 111/j.0008-4085.2004.00255.x.

Cunha, M., Sarmento, P., \& Vasconcelos, H. (2014). Uncertain efficiency gains and merger policy. Discussion paper.

Datta, D. K., Pinches, G. E., \& Narayanan, V. (1992). Factors influencing wealth creation from mergers and acquisitions: A meta-analysis. Strategic Management Journal, 13, 67-84. https://doi. org/10.1002/smj.4250130106. 
Davidson, C., \& Mukherjee, A. (2007). Horizontal mergers with free entry. International Journal of Industrial Organization, 25, 157-172. https://doi.org/10.1016/j.ijindorg.2006.03.003.

Deneckere, R., \& Davidson, C. (1985). Incentives to form coalitions with Bertrand competition. The RAND Journal of Economics, 16, 473-486. https://doi.org/10.2307/2555507.

Diesenhaus, J. L. (1987). Competitor standing to challenge a merger of rivals: The applicability of strategic behavior analysis. California Law Review, 75, 2057-2115. https://doi.org/10.2307/3480548.

Durande, S., \& Williams, K. (2005). The practical impact of the exercise of the right to be heard: A special focus on the effect of oral hearings and the role of the hearing officers. Competition Policy Newsletter, 2, 22-28.

Duso, T., Gugler, K., \& Yurtoglu, B. (2010). Is the event study methodology useful for merger analysis? A comparison of stock market and accounting data. International Review of Law and Economics, 30, 186-192. https://doi.org/10.1016/j.irle.2010.02.001.

Duso, T., Gugler, K., \& Yurtoglu, B. B. (2011). How effective is European merger control? European Economic Review, 55, 980-1006. https://doi.org/10.1016/j.euroecorev.2011.04.003.

Farrell, J. (2012). Market data and participants' views in horizontal merger analysis. Concurrences Law \& Economics, 2, 21-26.

Farrell, J., \& Rabin, M. (1996). Cheap talk. The Journal of Economic Perspectives, 10, 103-118. https:// doi.org/10.1257/jep.10.3.103.

Farrell, J., \& Shapiro, C. (2001). Scale economies and synergies in horizontal merger analysis. Antitrust Law Journal, 68, 685-710. https://www.jstor.org/stable/40843493.

Faulí-Oller, R., \& Motta, M. (1996). Managerial incentives for takeovers. Journal of Economics \& Management Strategy, 5, 497-514. https://doi.org/10.1111/j.1430-9134.1996.00497.x.

Fridolfsson, S.-O., \& Stennek, J. (2005). Why mergers reduce profits and raise share prices-a theory of preemptive mergers. Journal of the European Economic Association, 3, 1083-1104. https://doi. org/10.1162/1542476054729455.

González, A. (2007). Eliciting information from interested parties in merger control. Discussion paper, .

Gürtler, O., \& Kräkel, M. (2009a). Hostile takeover and costly merger control. Public Choice, 141, 371389. https://doi.org/10.1007/s11127-009-9457-4.

Gürtler, O., \& Kräkel, M. (2009b). On the inefficiency of merger control. Economics Letters, 102, 53-55. https://doi.org/10.1016/j.econlet.2008.11.009.

Harker, M., Hviid, M., \& Wright, K. (2011). The EU rules on standing in merger cases: should firms have to demonstrate "harm to competition"? European Law Review, 36, 500-523.

Heller, C.-P. (2015). On informational asymmetries in merger policy. BDPEMS Working Paper.

Heubeck, S., Smythe, D. J., \& Zhao, J. (2006). A note on the welfare effects of horizontal mergers in asymmetric linear oligopolies. Annals of Economics and Finance, 7, $29-47$.

Huck, S., Konrad, K. A., \& Müller, W. (2001). Big fish eat small fish: On merger in Stackelberg markets. Economics Letters, 73, 213-217. https://doi.org/10.1016/S0165-1765(01)00490-6.

Huck, S., Konrad, K. A., \& Müller, W. (2004). Profitable horizontal mergers without cost advantages: The role of internal organization, information and market structure. Economica, 71, 575-587. https ://doi.org/10.1111/j.0013-0427.2004.00389.x.

Hundt, R. (2011). Wireless: The common medium of conversation. Media Law \& Policy, 20, 95-117.

Kräkel, M., \& Müller, D. (2015). Merger efficiency and managerial incentives. International Journal of Industrial Organization, 41, 51-63. https://doi.org/10.1016/j.ijindorg.2015.05.004.

Krishna, V., \& Morgan, J. (2008). Cheap talk. In S.N. Durlauf, \& L.E. Blume (Eds.), The New Palgrave dictionary of economics (Vol. 1-8, pp. 751-756). London: Palgrave Macmillan UK. https://doi. org/10.1007/978-1-349-58802-2_221.

Lagerlöf, J., \& Heidhues, P. (2005). On the desirability of an efficiency defense in merger control. International Journal of Industrial Organization, 23, 803-827. https://doi.org/10.1016/j.ijind org.2005.08.005.

Lahiri, S., \& Ono, Y. (1988). Helping minor firms reduces welfare. The Economic Journal, 98, 11991202. https://doi.org/10.2307/2233727.

Lommerud, K. E., Straume, O. R., \& Sorgard, L. (2001). Merger profitability in unionized oligopoly. CEPR discussion paper no. 2738.

Lyons, B. R. (2003). Could politicians be more right than economists? A theory of merger standards. EUI working paper (RSC No. 2003/14).

Matsusaka, J. G. (1993). Takeover motives during the conglomerate merger wave. The RAND Journal of Economics, 24, 357-379. https://doi.org/10.2307/2555963. 
Mialon, S. H. (2008). Efficient horizontal mergers: The effects of internal capital reallocation and organizational form. International Journal of Industrial Organization, 26, 861-877. https://doi. org/10.1016/j.ijindorg.2007.07.004.

Milgrom, P., \& Roberts, J. (1986). Relying on the information of interested parties. The RAND Journal of Economics, 17, 18-32. https://doi.org/10.2307/2555625.

Miller, N. H. (2014). Modeling the effects of mergers in procurement. International Journal of Industrial Organization, 37, 201-208. https://doi.org/10.1016/j.ijindorg.2014.10.001.

Miller, N. H., \& Weinberg, M. (2014). Mergers facilitate tacit collusion: An empirical investigation of the Miller/Coors joint venture. Discussion paper.

Motta, M. (2004). Competition policy: Theory and practice. Cambridge: Cambridge University Press.

Neven, D., \& Röller, L.-H. (2002). Discrepancies between markets and regulators: an analysis of the first ten years of EU merger control. In K. Lundvall (Ed.), The pros and cons of merger control: 10th anniversary of the swedish competition authority (pp. 13-38). Konkurrensverket (Swedish Competition Authority).

Neven, D. J., \& Röller, L.-H. (2005). Consumer surplus vs. welfare standard in a political economy model of merger control. International Journal of Industrial Organization, 23, 829-848. https://doi. org/10.1016/j.ijindorg.2005.08.011.

Nocke, V., \& Whinston, M. D. (2010). Dynamic merger review. Journal of Political Economy, 118, 1200-1251. https://doi.org/10.1086/658161.

Perry, M. K., \& Porter, R. H. (1985). Oligopoly and the incentive for horizontal merger. The American Economic Review, 75, 219-227. https://www.jstor.org/stable/1812716.

Pittman, R. W. (2007). Consumer surplus as the appropriate standard for antitrust enforcement. Discussion paper.

Riley, J. G. (2001). Silver signals: Twenty-five years of screening and signaling. Journal of Economic Literature, 39, 432-478. https://doi.org/10.1257/jel.39.2.432.

Roll, R. (1986). The hubris hypothesis of corporate takeovers. Journal of Business, 59, 197-216. https:// www.jstor.org/stable/2353017.

Salant, S. W., Switzer, S., \& Reynolds, R. J. (1983). Losses from horizontal merger: The effects of an exogenous change in industry structure on Cournot-Nash equilibrium. The Quarterly Journal of Economics, 98, 185-199. https://doi.org/10.2307/1885620.

Salinger, M. A. (1988). Vertical mergers and market foreclosure. The Quarterly Journal of Economics, 103, 345-356. https://doi.org/10.2307/1885117.

Sørgard, L. (2009). Optimal merger policy: Enforcement vs. deterrence. The Journal of Industrial Economics, 57, 438-456. https://doi.org/10.1111/j.1467-6451.2009.00389.x.

Spence, M. (1973). Job market signaling. The Quarterly Journal of Economics, 87, 355-374. https://doi. org/10.2307/1882010.

Stigler, G. J. (1950). Monopoly and oligopoly by merger. The American Economic Review, 40, $23-34$. https://www.jstor.org/stable/1818020.

Stiglitz, J. E. (2002). Information and the change in the paradigm in economics. American Economic Review, 92, 460-501. https://www.jstor.org/stable/3083351.

Stucke, M. E., \& Grunes, A. P. (2012). The AT\&T/T-mobile merger: What might have been? Journal of European Competition Law \& Practice, 3, 196-205. https://doi.org/10.1093/jeclap/lps019.

Van Arsdall, M. G., \& Piehl, M. J. (2014). The evolving role of competitors in merger review. Crowell \& Moring LLP, Law360 client information.

Van Bael \& Bellis. (2005). Competition law of the European community. Kluwer Law International.

Vasconcelos, H. (2010). Efficiency gains and structural remedies in merger control. The Journal of Industrial Economics, 58, 742-766. https://doi.org/10.1111/j.1467-6451.2010.00436.x.

Vermeulen, F., \& Barkema, H. (2001). Learning through acquisitions. Academy of Management journal, 44, 457-476. https://doi.org/10.5465/3069364.

Werden, G. J., Joskow, A. S., \& Johnson, R. L. (1991). The effects of mergers on price and output: Two case studies from the airline industry. Managerial and Decision Economics, 12, 341-352. https:// doi.org/10.1002/mde.4090120502.

Williamson, O. E. (1968). Economies as an antitrust defense: The welfare tradeoffs. The American Economic Review, 58, 18-36. https://www.jstor.org/stable/1831653.

Publisher's Note Springer Nature remains neutral with regard to jurisdictional claims in published maps and institutional affiliations. 